\title{
Diverse Response of Three Sweetpotato Cultivars to Abiotic Stresses and Adjustment of Free Polyamine Levels
}

\author{
Mervat M.M. El-Far ${ }^{(1,3,4) \#, ~ T h o m a s ~ B e r b e r i c h ~}{ }^{(2,3)}$, Hans-Werner Koyro ${ }^{(4)}$ \\ (1)Agricultural Genetic Engineering Research Institute (AGERI), Agricultural \\ Research Centre (ARC), Giza, Egypt; (2) Phytoprove GmbH, Frankfurt am Main, \\ Germany; ${ }^{(3)}$ Senckenberg Biodiversity and Climate Research Center, Frankfurt am \\ Main, Germany; (4)Institute for Plant Ecology, Justus-Liebig-University, Gießen, \\ Germany.
}

\begin{abstract}
$\mathbf{T}$ HREE SWEETPOTATO cultivars, Abees, Mogamba and Santo Amaro, were subjected to moderate $(-0.5 \mathrm{MPa})$ and severe drought stress $(-2.5 \mathrm{MPa})$ or to salt treatments up to $200 \mathrm{mM}$ $\mathrm{NaCl}$, respectively. Patterns of leaf polyamine contents were analyzed to verify whether these metabolites could be used as early traits of tolerance. Physiological parameters like leaf relative water content, total chlorophyll content, leaf electron conductance, stomata resistance and transpiration rate were used to indicate stress conditions of the plants and growth parameters were applied to identify the level of tolerance among the used cultivars. In all three cultivars, drought led to an increase of putrescine (Put) and decrease of spermidine (Spd) concentrations while spermine (Spm) was decreased only in the Santo Amaro cultivar. The most tolerant cultivar was Mogamba followed by Santo Amaro and Abees. However, this descending order was not reflected by the specific changes in polyamine levels but it is altered under drought as well as under salinity in both sensitive and tolerant cultivars. More investigations are needed to figure out if polyamines behave as a response of stress and/or a protective mechanism.
\end{abstract}

Keywords: Drought stress, Polyamines, Salt stress, Sweetpotato, Ipomoea batatas.

List of abbreviations: $\mathrm{ABA}=\mathrm{Abscisic}$ acid, $\mathrm{ANOVA}=$ One-way analysis of variance, $\mathrm{EL}=$ Electrolyte leakage, HPLC $=$ High-performance liquid chromatography, LEC $=$ Leaf electric conductance, $\mathrm{MPa}=$ Megapascal, $\mathrm{PA}=$ Polyamines, $\mathrm{Put}=$ Putrescine, $\mathrm{ROS}=$ Reactive oxygen species, $\mathrm{Rs}=$ Stomatal resistance, $\mathrm{RWC}=$ Relative water content, $\mathrm{SD}=\mathrm{Standard}$ deviation, $\mathrm{SEC}=$ Soil electron conductance, $\mathrm{Spd}=$ Spermidine, $\mathrm{Spm}=$ Spermine, $\mathrm{Tr}=$ Transpiration, $\mathrm{T}-\mathrm{Spm}=$ Thermospermine.

\section{Introduction}

Climate change causes extreme weather events such as high temperatures, severe droughts and salinization of soil due to irrigation. Such extreme weather variability is the primary reason for the loss of agricultural productivity worldwide, reducing average yields for most major crop plants by more than $50 \%$ and considered as major threats to food security (FAO, 2012). As a consequence there is a need in crop varieties that can tolerate the changing environmental conditions posing a challenge for breeders. It is highly desirable to develop a reliable tool that can be used to identify tolerant plant cultivars.
Polyamines are negatively charged aliphatic polycations, that are present in all living organisms and have been associated with stress responses in plants (Berberich et al., 2015). The polyamines putrescine (Put, a diamine), spermidine ( $\mathrm{Spd}$, a triamine), and spermine (Spm, a tetraamine) were found to be involved in a large number of cellular processes, including cell growth and proliferation, modulation of chromatin structure, DNA stabilization, gene transcription and translation, signal transduction, membrane stability, functioning of ion channels and receptor-ligand interactions and tumour development (Landau et al., 2012). In plants, increased Put, Spd and Spm levels can be engaged in metabolically highly active tissues during development and under stress

\#Corresponding author email: elfarmervat@hotmail.com DOI: 10.21608/ejbo.2019.6752.1269 
conditions (Shabala \& Munns, 2017). In the latter case, earlier studies have suggested that polyamines such as Spd, Spm, T-Spm (thermospermine, another tetraamine) and their precursor Put may increase several-fold under dry or saline conditions (Tabor \& Tabor, 1985). Similar effects were shown in response to adverse environmental conditions including flooding, temperature extremes, UV, heavy metal and herbicide toxicity and wounding (Tabor \& Tabor 1985 and Liu et al., 2007), where it is proposed to be involved in modulating the homeostasis of reactive oxygen species (ROS) by their direct, or indirect regulation of antioxidant systems or suppression of ROS production (Liu et al. 2007; Mostofa et al., 2014 and Biswas \& Mano, 2015).

Sweetpotato (Ipomoea batatas (L.) Lam.) ranking as the world's seventh important crop is cultivated in more than 100 countries with a wide range of climate (FAO, 2008). It is a versatile crop with higher biological efficiency as food and feed as well as in industrial applications. It is regarded as a food security crop because of its low input requirements, ease of production and ability to produce under adverse weather and soil conditions (Ndolo et al., 2001). Attempts to improve resistance to a specific stress within a given species will be enhanced by understanding the differences in the physiological background between species or varieties in response to that stress. Polyamines can be an important component for the survival in harsh site conditions and it can be expected, that polyamines play an important role in the stress resistance of sweetpotato and agricultural suitability in adverse environmental conditions (Kasukabe et al., 2006).

Therefore, knowledge of the effects of abiotic stresses on the endogenous free levels of polyamines and the involvement in a metabolic adjustment in sweetpotato would build a base for implementing polyamine metabolism in breeding approaches to improve sweetpotato production under stress conditions. The aim of this study was to explore the future prospects of sweetpotato at drought and salinity stresses. We analyzed the variability of free polyamine levels in different sweetpotato cultivars in response to drought and salinity stress.

\section{Materials and Methods}

Genotypes used

In this study, we used three cultivars of sweetpotato (Ipomoea batatas (L.) Lam: The local Egyptian sweetpotato cultivar Abees, the accession 440034 Mogamba (origin, Burundi) and the accession 400011 Santo Amaro (origin, Brazil). The latter both were obtained from the International Potato Centre (CIP), Lima, Peru and selected for this work according to their productivity, chemical characteristics, and organoleptic properties (EL-Bastawesy et al., 2008 and El-Far \& Koyro, 2014).

\section{Plant growth conditions}

The first part of the experiment which included the drought and salinity treatments and the physiological measurements was carried out in the Institute of Plant Ecology, Justus-LiebigUniversity, Germany, while the extraction and analysis of the polyamines were performed at the Senckenberg Biodiversity and Climate Research Center (SBiK-F), Frankfurt am Main, Germany.

One week old rooted cuttings were planted into individual plastic pots with $16 \mathrm{~cm}$ diameter filled with one $\mathrm{kg}$ experimental soil (mass ratio $1: 1: 1$, beat moss: sand: clay). Pots were placed in a greenhouse at temperatures of $28 / 25^{\circ} \mathrm{C}$ (day/night), and a long-day photoperiod (16/8hr, light/dark) with an irradiance of $200 \mu \mathrm{mol} \mathrm{m} \mathrm{m}^{-2} \mathrm{~s}^{-1}$ and $50-60 \%$ relative air humidity. Plants were grown under wellwatered conditions $(70 \%$ water holding capacity $=$ $30 \%$ volumetric water content (controlled with an HH2 moisture meter, Delta-T Devices Ltd). One rooted cutting/pot was used as a biological replica, three biological replicates were used/treatment. At the stage of eight fully expended leaves (age of 4 weeks) a part of the plants was subjected to drought or salinity. Measurements and analysis were carried out on the third fully expanded leaf from the top. Three biological replicates were used for the statistical analysis.

\section{Drought stress treatment}

Pots were left with reduced irrigation to dry gradually until $5 \%$ soil water content prior to sample collection (moderate drought $=-0.5 \mathrm{MPa}$ ) and until $0 \%$ volumetric water content (severe drought $=-2.5 \mathrm{MPa}$ ). The soil water potential was measured by a (Psypropsychrometer, Wescor, Utah, USA). Control plants were kept under wellwatered conditions as described above until the end of the experiment. The samples recovered from the stress were obtained after $1 \mathrm{hr}$ of watering the plants that were prior exposed to -0.5 and -2.5 $\mathrm{MPa}$. 


\section{Salinity stress treatment}

Four weeks following plantation, plants were watered twice a week with $50 \mathrm{ml}$ each of 50,100 , 150 and 200mM NaCl, respectively. Samples were collected at the age of eight weeks. SEC (Soil electron conductance) was measured using a WET Sensor and an $\mathrm{HH} 2$ Moisture Meter (Delta-T-Device). Four weeks following salinity treatments, three plants per treatment were harvested as three biological replicates. Fresh weight of roots, stems and leaves were recorded. Plant materials were dried at $105^{\circ} \mathrm{C}$ for $72 \mathrm{hr}$ to determine the percentage of dry weight and water content for roots, stems and leaves. The $50 \%$ reduction of growth was calculated for each variety on the base of regression curves.

\section{Relative water content ( $R W C$ )}

Leaf disks with a diameter of $0.5 \mathrm{~cm}$ were collected and fresh weight was determined. Disks were floated on the surface of the water in Petri dishes at room temperature for $5 \mathrm{hr}$ and the turgid weight was measured. Discs were then dried by incubation at $70^{\circ} \mathrm{C}$ for overnight and RWC was calculated as described by Smart \& Bingham (1974), were RWC $(\%)=[($ Fresh weight- dry weight)/(turgid weight- dry weight)]* 100

\section{Total chlorophyll content (SPAD)}

SPAD readings were collected using the mean of three SPAD readings for each leaf by the chlorophyll meter (SPAD-502, Minolta Co., Osaka, Japan).

\section{Stomatal resistance $(R s)$ and transpiration rate} (Tr)

Rs and Tr were measured early at the morning using a portable steady-state porometer (LI 1600 M, LICOR). Measurements were carried out on three sample leaves per treatment.

\section{Leaf electric conductance (LEC)}

EC of leaf samples of salt treated and control plants of sweetpotato were determined as described by Koti et al. (2007) with modifications. $200 \mathrm{mg}$ of freshly prepared leaf discs were immersed in a tube with $10 \mathrm{ml}$ de-ionized water after washing its surface. The conductivity of the solution was measured with a conductivity meter (Aqua Lytic, Model L17, Bischof), readings were recorded as zero time $\left(\mathrm{t}_{0}\right)$. Samples were frozen under liquid $\mathrm{N}_{2}$ for $20 \mathrm{~min}$. Conductivity was measured again when the solution was warmed up to room temperature $\left(t_{\text {end }}\right)$. The percentage of electrolyte leakage (EL) was calculated using the formula, EL \%=1- [(1- $\left.\left(\mathrm{ECt}_{0} /\right) / 1-\left(\mathrm{ECt}_{\text {end }}\right)\right)-$ (Control samples at zero time/control samples after freezing) $]^{*} 100$.

\section{Sample collection}

The third leaf (first fully expanded leaf) of each plant from each pot was collected as one biological replica for the drought and salinity treatments. Three biological replicas per treatment were used for the free polyamines measurements. In parallel, non-treated plant materials were collected at the same time. Samples were frozen under liquid nitrogen and lyophilized (Christ BEATA 1-8lyophilizer with LMC-2 system control, Martin Christ GmbH).

\section{Polyamines extraction and analysis}

Polyamines were extracted following the method described by Naka et al. (2010) with the modification that the extraction was carried out using lyophilized leaf materials. Forty $\mathrm{mg}$ leaf materials were extracted, benzoylated and analyzed by high-performance liquid chromatography (HPLC, Agilent Technology 1260 Infinity Quaternary LC System, Diode Array Detector (DAD), TOSOH 4.6 x $250 \mathrm{~mm}$, TSK-GEL ODS-80Ts column) using methanol as a mobile phase. Extracted free polyamines were compared to the polyamines standard profile prepared following the method of Naka et al. (2010). Three biological replicates were used for each treatment and cultivar.

\section{Statistical analysis}

One-way analysis of variance (ANOVA) test using Dunnat analysis for the RWC, LEC, and SPAD or the unpaired t-test for the stomata resistance and transpiration were applied to assess the significance of the differences between the control and the stress treatments (drought and salinity experiments) separately at $\mathrm{P}<0.05$. Values were calculated using three biological replicates for each treatment. All datasets shown are presented as the means \pm standard deviation (SD). Significant changes were marked with one $(\mathrm{P} \leq 0.05)$, two $(\mathrm{P} \leq 0.01)$ or three $(\mathrm{P} \leq 0.001)$ asterisks.

\section{$\underline{\text { Results }}$}

\section{Growth parameters}

Drought led to a significant reduction of growth in all three cultivars (Fig. 1). However, 
it was proportionally highest in Abees (-28.2\%) followed by Mogamba (-24.6\%) and Santo Amaro $(-19.9 \%)$. As salinity increased, the growth of all three cultivars decreased (Fig. 2). A 50\% reduction of growth was reached at $76.2 \mathrm{mM} \mathrm{NaCl}$ in Abees followed by Santo Amaro $(110 \mathrm{mM} \mathrm{NaCl})$ and Mogamba (129.3mM NaCl).

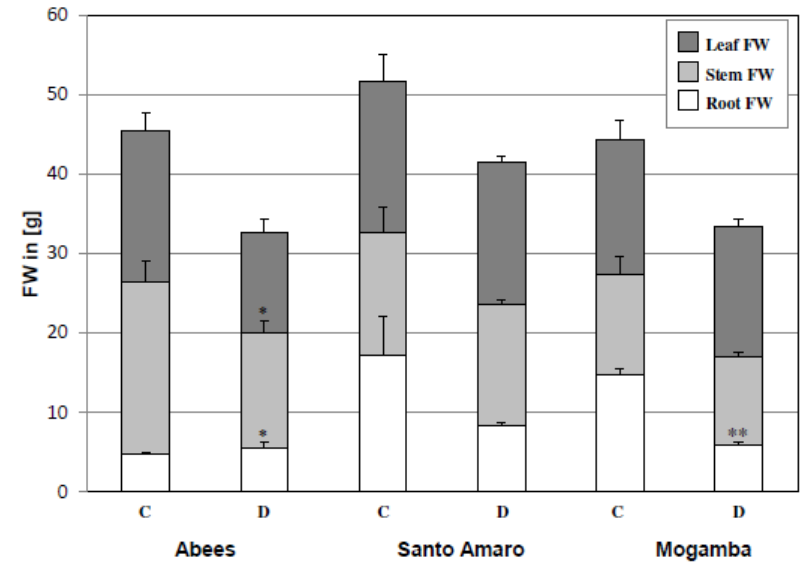

Fig. 1. Effect of drought treatment (D) on fresh weight (FW) of leaves, stem and roots of three sweetpotato cultivars in comparison to control (C). Values $\pm \mathrm{SE}$ of three independent replicates are shown [Significance levels are indicated as $\mathbf{P}<0.1(* *)$ and $\mathbf{P}<0.05(*)$ in comparison to the control].

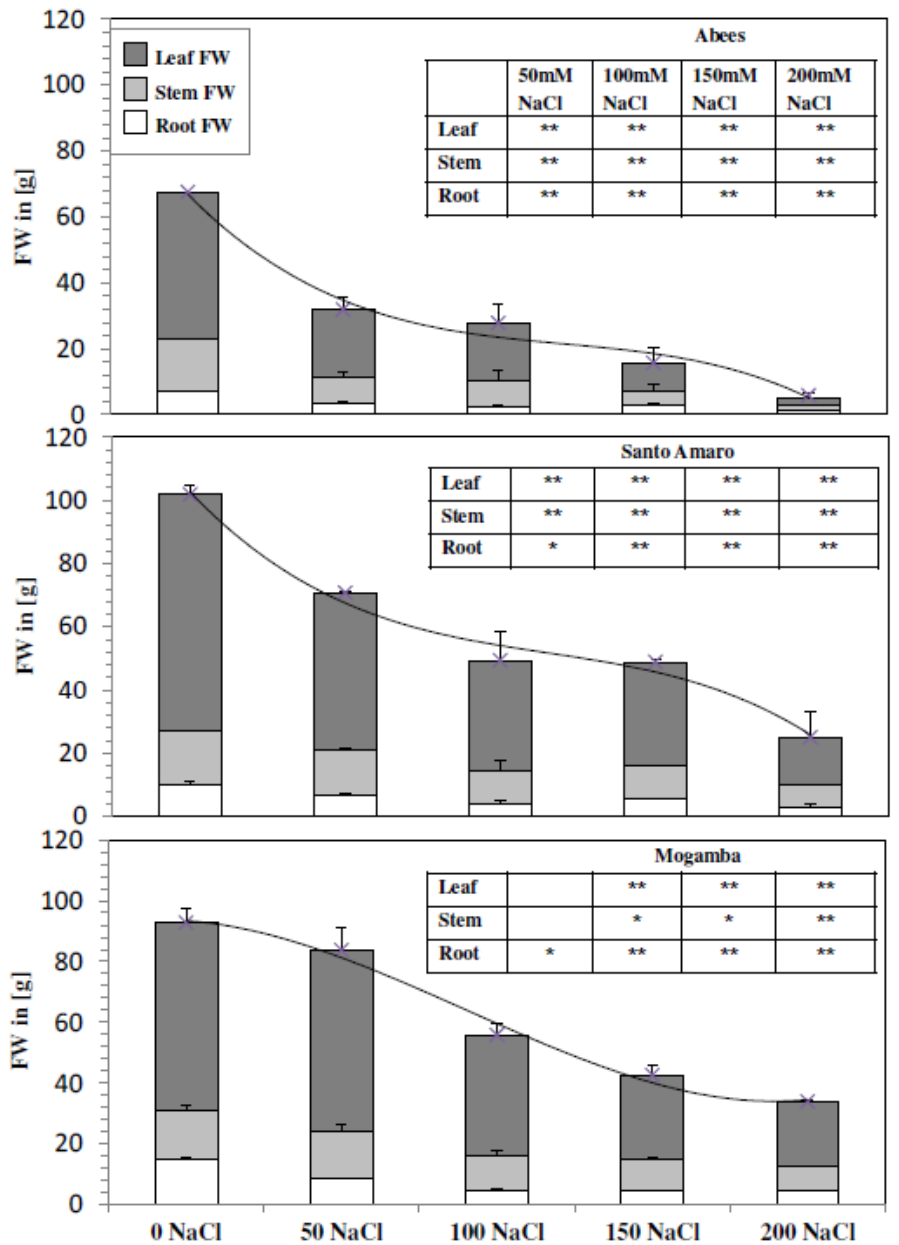

Fig. 2. Effect of salinity treatment on fresh weight (FW) of leaves, stem and roots of three sweetpotato cultivars. Values $\pm \mathrm{SE}$ of three independent replicates are shown [Significance levels are indicated as $\mathrm{P}<0.1(* *)$ and $\mathrm{P}<0.05$ $(*)$ in comparison to the control $(0 \mathrm{mM} \mathrm{NaCl})]$. 
Physiological measurements

RWC of plants following drought stress was reduced significantly $89.6 \pm 3.11 \%$ (control) to $81.8 \pm 2.12 \%$ (moderate drought) and $74.4 \pm 1.67 \%$ (severe drought) for the cultivar Abees. Similar results were indicated for the cultivar Santo Amaro, where RWC was reduced significantly from $92.8 \pm 1.97 \%$ to $76.6 \% \pm 1.39$ and $73.6 \% \pm$ 4.01 following moderate drought and severe drought treatments. On the other hand, the cultivar
Mogamba did not show significant difference among drought treatments and control (Table 1).

In the salt stress treatments, RWC of all used cultivars did not indicate any significant changes when compared to control plants (Table 2). Meanwhile, LEC was significantly increased in response to all salt stress treatments in all the cultivars when compared to the values of control plants (Table 2).

TABLE 1. Means of leaf relative water content (RWC), chlorophyll meter (SPAD), transpiration, stomata resistance of sweetpotato cultivars used in this study following moderate drought $(-0.5 \mathrm{MPa})$, severe drought $(-2.5 \mathrm{MPa})$ and their respective recovery treatments in comparison to controls.

\begin{tabular}{|c|c|c|c|c|c|c|c|c|c|}
\hline \multicolumn{2}{|l|}{ Parameter } & \multicolumn{2}{|c|}{ RWC (\%) } & \multicolumn{2}{|c|}{ SPAD } & \multicolumn{2}{|c|}{$\begin{array}{c}\text { Transpiration } \\
\text { mol } \mathrm{m}-2 \mathrm{~s}^{-1}\end{array}$} & \multicolumn{2}{|c|}{$\begin{array}{c}\begin{array}{c}\text { Stomata resistances } \\
\mathbf{c m}^{-1}\end{array} \\
\end{array}$} \\
\hline Cultivar & Treatment & Mean & SD & Mean & SD & Mean & SD & Mean & SD \\
\hline \multirow{5}{*}{ Abees } & Control & 89.6 & \pm 3.11 & 31.9 & \pm 0.49 & 0.84 & \pm 0.12 & 15.4 & \pm 2.3 \\
\hline & $\begin{array}{l}\text { Moderate } \\
\text { drought }\end{array}$ & $81.8^{*}$ & \pm 2.12 & $40.2 * *$ & \pm 0.53 & $0.36^{* *}$ & \pm 0.03 & $35.5 * *$ & \pm 3.15 \\
\hline & $\begin{array}{l}\text { Moderate } \\
\text { drought } \\
\text { recovery }\end{array}$ & 88 & \pm 2.97 & $38.7 * *$ & \pm 0.62 & $0.59 * *$ & \pm 0.02 & $20.5^{*}$ & \pm 0.45 \\
\hline & Severe drought & $74.4 * *$ & \pm 3.21 & $43.9^{* *}$ & \pm 2.17 & $0 * *$ & \pm 0 & $0 * *$ & \pm 0 \\
\hline & $\begin{array}{l}\text { Severe drought } \\
\text { ecovery }\end{array}$ & $78.3 * *$ & \pm 1.67 & $41.8^{* *}$ & \pm 1.1 & $0 * *$ & \pm 0 & $0^{* *}$ & \pm 0 \\
\hline \multirow{5}{*}{ SantoAmaro } & Control & 92.8 & \pm 1.97 & 32.5 & \pm 0.25 & 1.9 & \pm 0.067 & 8.3 & \pm 0.26 \\
\hline & $\begin{array}{l}\text { Moderate } \\
\text { drought }\end{array}$ & $76.6^{* *}$ & \pm 1.39 & $39.4 * *$ & \pm 0.75 & $0.27 * *$ & \pm 0.08 & $48.7 * *$ & \pm 15.6 \\
\hline & $\begin{array}{l}\text { Moderate } \\
\text { drought } \\
\text { recovery }\end{array}$ & $84.6^{*}$ & \pm 3.76 & 34.6 & \pm 1.47 & $0.42 * *$ & \pm 0.1 & $29.8^{*}$ & \pm 7.8 \\
\hline & Severe drought & $73.6^{* *}$ & \pm 4.01 & $43.7 * *$ & \pm 2.3 & $0 * *$ & \pm 0 & $0 * *$ & \pm 0 \\
\hline & $\begin{array}{l}\text { Severe drought } \\
\text { recovery }\end{array}$ & $77.8^{* *}$ & \pm 1.53 & $43.1 * *$ & \pm 2.1 & $0 * *$ & \pm 0 & $0^{* *}$ & \pm 0 \\
\hline \multirow{5}{*}{ Mogamba } & Control & 81.5 & \pm 5.92 & 34.3 & \pm 1.7 & 1.19 & \pm 0.07 & 12.4 & \pm 0.79 \\
\hline & $\begin{array}{l}\text { Moderate } \\
\text { drought }\end{array}$ & 81 & \pm 8.06 & 39.6 & \pm 1.8 & $0.18^{* *}$ & \pm 0.024 & $86.1 * * *$ & \pm 12.9 \\
\hline & $\begin{array}{l}\text { Moderate } \\
\text { drought } \\
\text { recovery }\end{array}$ & 79 & \pm 0.95 & 38.3 & \pm 1.8 & $0.15^{* *}$ & \pm 0.032 & $77 * *$ & \pm 44.18 \\
\hline & Severe drought & 76 & \pm 3.06 & $45.3 * *$ & \pm 2.6 & $0.05^{* *}$ & \pm 0.06 & $0 * *$ & \pm 0 \\
\hline & $\begin{array}{l}\text { Severe drought } \\
\text { recovery }\end{array}$ & 77 & \pm 4.48 & $43.8^{* *}$ & \pm 4 & $0.08 * *$ & \pm 0.046 & $127.7 * *$ & \pm 61.6 \\
\hline
\end{tabular}

Standard deviation (SD) was calculated using three individual measurements. One way ANOVA test was used to asses the significance of differences at $\mathrm{P} \leq 0.05(*), \mathrm{P} \leq 0.01(* *)$ and $\mathrm{P} \leq 0.001(* * *)$ between treatments and their respective controls. 


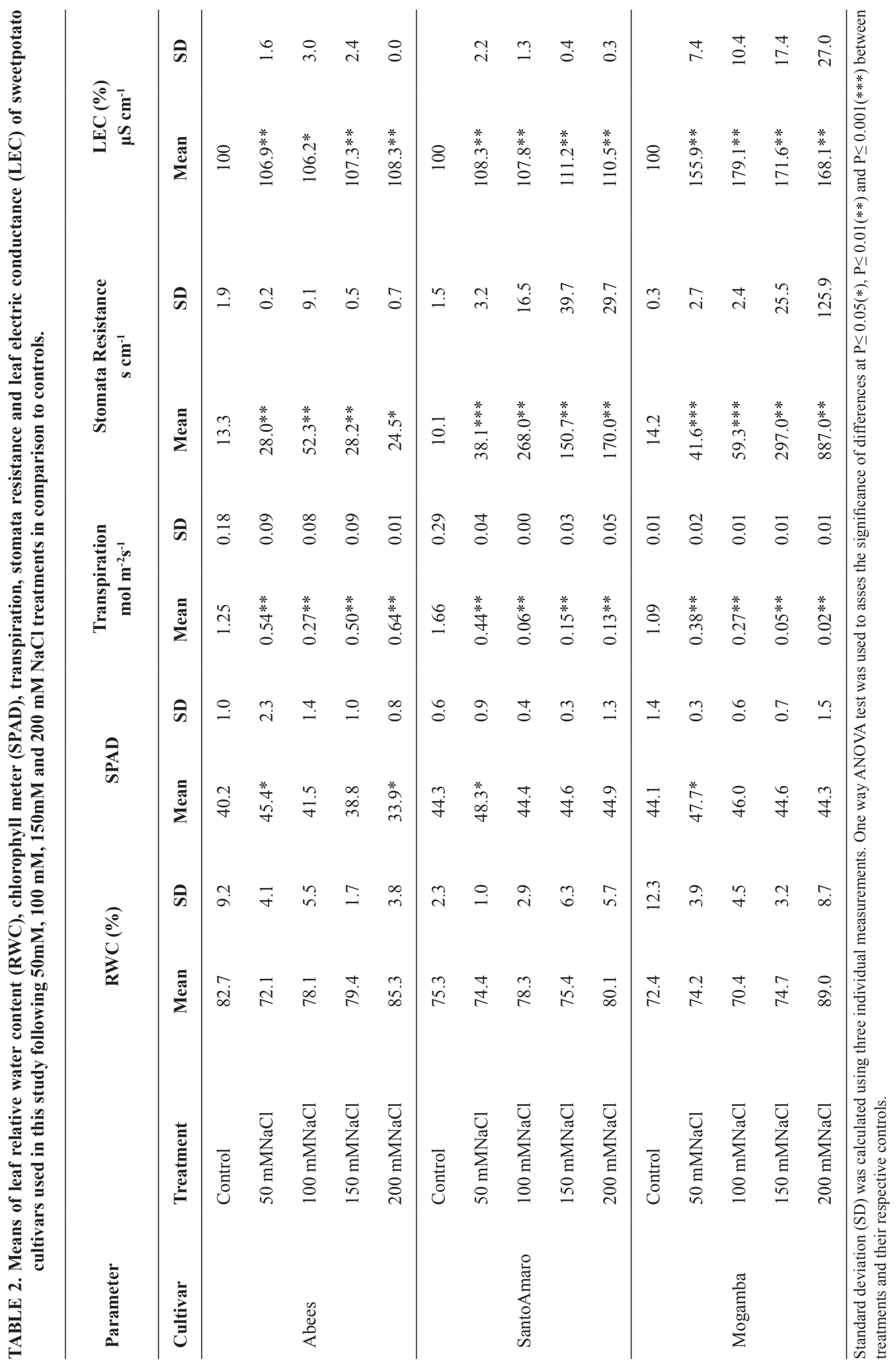

Egypt. J. Bot. 59, №.2 (2019) 
Total chlorophyll content of Abees and Santo Amaro plants increased significantly at moderate and severe drought treatments. On the other hand, the cultivar Mogamba showed a significant difference only at the severe drought treatment $(45.3 \pm 2.6)$ when compared to the control plants (Table 1). Under salinity, a slight, significant and transient increase in chlorophyll content could be observed for all cultivars up to $50 \mathrm{mM} \mathrm{NaCl}$ salinity. However, the SPAD value of Abees was significantly lower at $200 \mathrm{mM} \mathrm{NaCl}$ as of controls and of the other two cultivars (Table 2).

Among all the physiological parameters used to determine the stress status of the plants, transpiration and stomata resistance showed a significant decrease and increase, respectively, between drought or salinity stress and control for all used sweetpotato cultivars (Tables 1 and 2).

\section{Polyamines content}

Although all four common plant polyamines (Put, Spd, Spm, and T-Spm) were included in the analyses with clear separation of Spm and T-Spm in standard mixes, no significant level of T-Spm was detected in the sweetpotato extracts. Drought and salinity led to very sophisticated responses in all three varieties. Drought led to a significant and high decrease of the concentration of the triamine Spd in all sweetpotato cultivars either at moderate or severe stress conditions (Fig. 3). A similar droughtinduced reduction happened for the tetramine Spm, but only in the cultivar Santo Amaro. The concentration of Put increased in contrast to Spd and Spm in all three cultivars. Abees presented a steady increase until severe drought, Santo Amaro a reasonable increase until moderate stress and Mogamba responded only at severe drought.

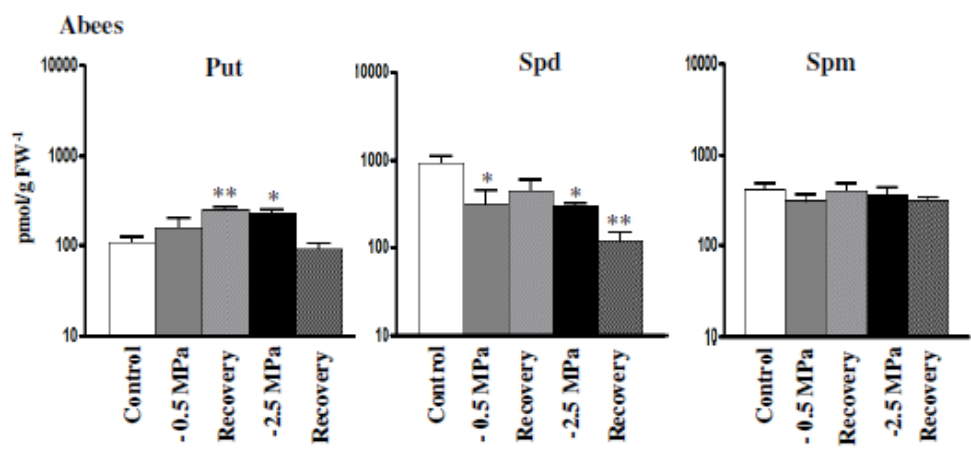

Santo Amaro
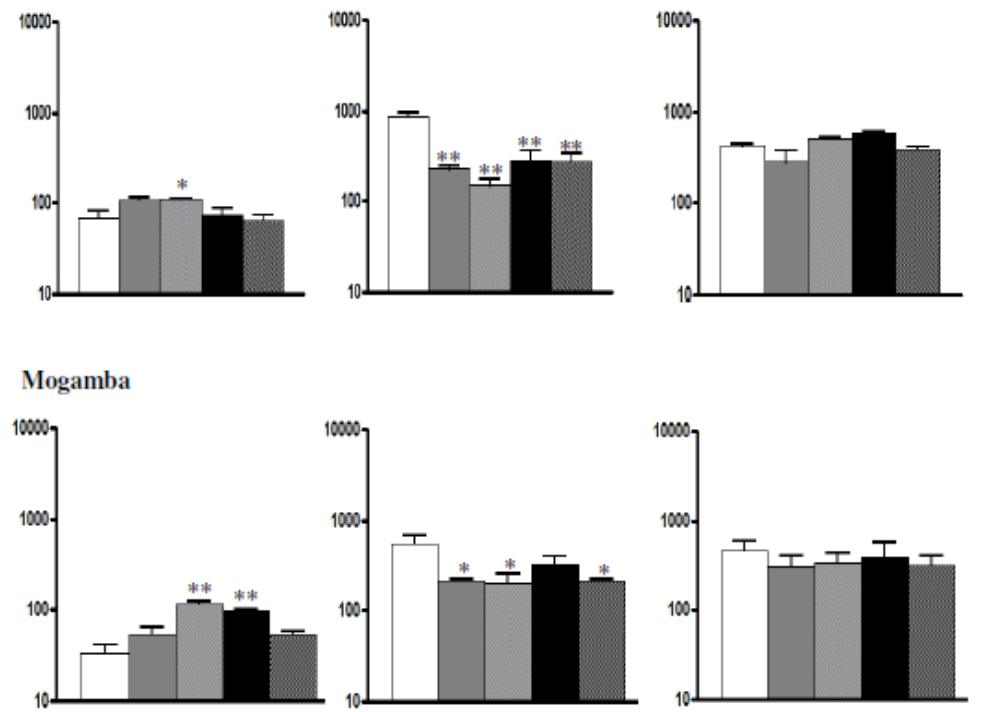

Fig. 3. Putrescine (Put), spermidine (Spd) and spermine (Spm) concentrations under moderate drought (-0.5 MPa), severe drought $(-2.5 \mathrm{MPa})$, and the respective recovery condition in comparison to control condition in three sweetpotato cultivars [Values $\pm \mathrm{SE}$ of three independent replicates are shown. Significance levels are indicated as: $\mathbf{P}<0.001(* * *), \mathbf{P}<0.01(* *), \mathbf{P}<0.05(*)$ in comparison to control. Scale of polyamines concentration (Y-axis) is represented in $\log 10]$. 
Salinity did not lead to any significant change of Spm in all three cultivars (Fig. 4). However, the Spd concentration increased with salinity at least transiently in all three cultivars with a maximum in Santo Amaro at $100 \mathrm{mM}$, in Mogamba at $150 \mathrm{mM}$ and Abees at $200 \mathrm{mM}$ $\mathrm{NaCl}$ salinity. The Put concentration increased transiently in Abees (max at $100 \mathrm{mM} \mathrm{NaCl}$ ) and Mogamba (max at $150 \mathrm{mM} \mathrm{NaCl}$ ) but dropped to control levels at high $\mathrm{NaCl}$ salinity. In contrast to these, Put concentration in Santo Amaro decreased steadily up to $200 \mathrm{mM} \mathrm{NaCl}$, finally reaching $20 \%$ of the control.
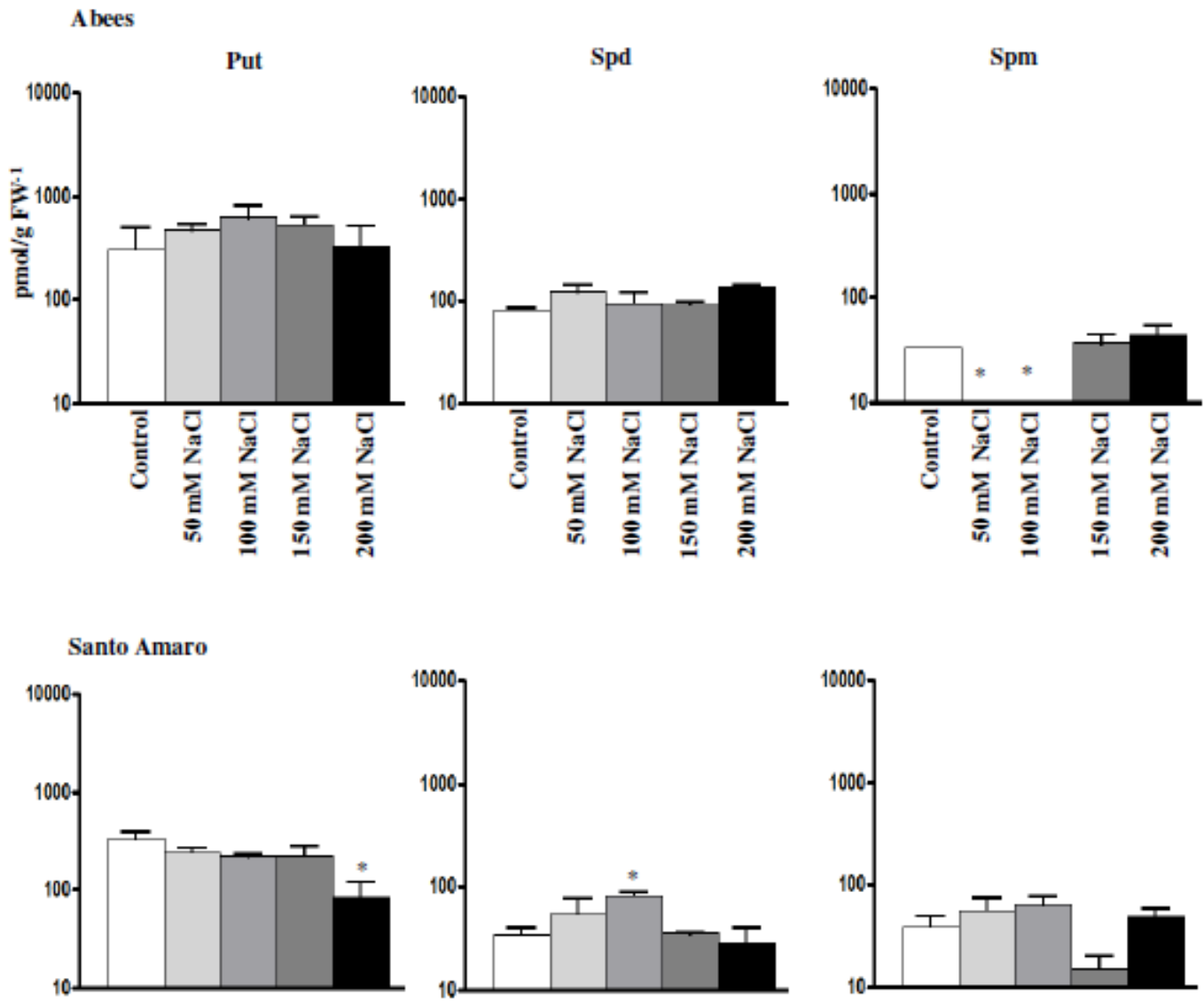

Mogamba
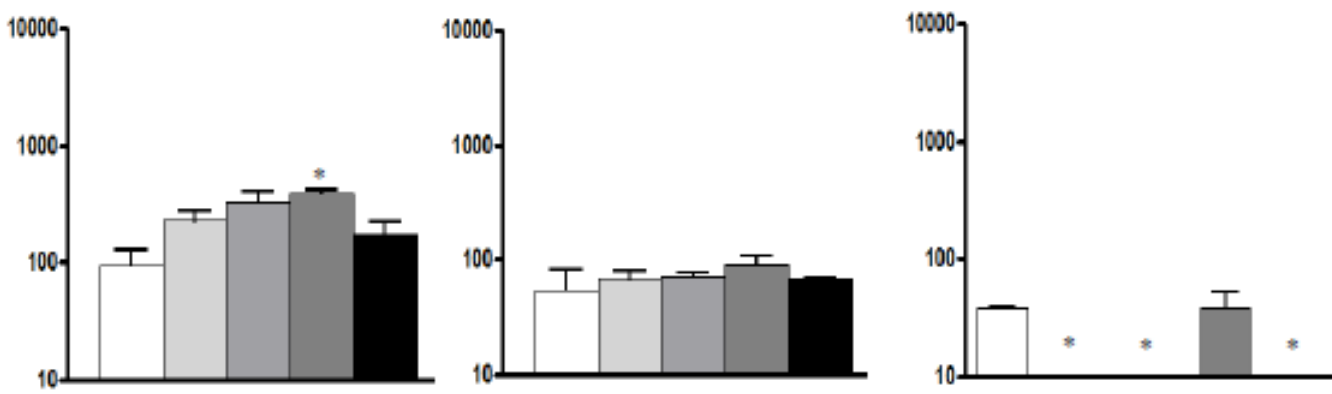

Fig. 4. Putrescine (Put), spermidine (Spd) and spermine (Spm) concentrations following treatment with $0 \mathrm{mM}$, $50 \mathrm{mM}, 100 \mathrm{mM}, 150 \mathrm{mM}$ and $200 \mathrm{mM} \mathrm{NaCl}$ in three sweetpotato cultivars [Values $\pm \mathrm{SE}$ of three independent replicates are shown. Significance levels are indicated as: $\mathbf{P}<0.001(* * *), \mathbf{P}<0.01(* *), \mathbf{P}<0.05(*)$ in comparison to control. Scale of polyamines concentration (Y-axis) is represented in $\log 10]$. 


\section{Discussion}

To cope with environmental stress factors, plants have evolved a spacious field of molecular programs to sense changes rapidly and adapt consequently (Kusano et al., 2008). It was shown that polyamines play a crucial role in various physiological and developmental approaches in plants with an impact on stress responses or stress tolerance. Elevating the PA pool in the plants by exogenous application or the overexpression of PA biosynthetic genes has been shown to give enhanced resistance to various stresses (Harindra Champa et al., 2015). On the other hand, high levels of PA are known to be harmful to plant cells, so sophisticated control of PA composition and concentration is required. Therefore, it was the aim of this study to correlate the stress response and adaptability of the three cultivars of sweetpotato with the growth response, several physiological parameters and the composition of polyamines.

Originally, we expected some analogy of results in the drought and salinity response of all three sweetpotato cultivars because of the mutual pressure on water relations and regulation of gas exchange (Shabala \& Munns, 2017) but we found instead more characteristic differences.

\section{Drought}

Drought led, e.g. in contrast to salinity to a significant reduction of the RWC in all three sweetpotato cultivars (Fig. 1). This might be explained by the possible cheap osmotic adjustment with $\mathrm{Na}^{+}$and $\mathrm{Cl}^{-}$in case of salinity instead of a more energy consuming adjustment with sugars and proline in case of drought (Yooyongwech et al., 2016). The relative low RWC at drought might also explain the increase of the chlorophyll content because of shrinkage of the tissues. However, it stands in clear contrast to the results of Yooyongwech et al. (2016) who found a reduction in chlorophyll content, but at more moderate conditions. The increase of chlorophyll content in all three cultivars in combination with the reduced transpiration and increased stomatal resistance gives evidence for oxidative stress because sweetpotato can sustain a relatively high photosynthetic activity under drought and alleviates functional deterioration (Kubota, 2003).
The physiological parameters do explain in principle the growth reduction at drought, but not the different sensitivity of the three studied cultivars of sweetpotato (Laurie et al., 2015). However, the result of the polyamine analysis enables assumptions for a possible differentiation. It seems as if the clear switch at moderate drought from Spd and Spm to Put accumulation helps Santo Amaro to initiate an early adjustment and to minimize the impact of severe drought. It seems as if Put acts as a stress sensor or mediator. There is a load of literature describing the correlation between endogenous PA titer and physiological disturbance and on the protective effect of PAs against abiotic stresses. Flores \& Galston (1982) found, that under a number of stresses, including water stress, osmotic shock, Put levels significantly increase. It was also demonstrated that exogenous applications of PAs successfully enhance tolerance to cold (Alcázar et al., 2011), drought (Liu et al., 2004), osmotic stress (Groppa $\&$ Benavides, 2008) and high temperature (Sagor et al., 2013). However, these findings do not point out if enhanced Put production is responsible for protection or higher levels are the result of the stress-induced injury. A simple explanation of the decreased levels of Spm and/or Spd in all three cultivars of sweetpotato may be the interaction in catabolism with the amino acid proline. Proline (Pro) levels often enhanced in response to diverse environmental stress conditions like drought while interactions between stress-induced Pro and PA accumulations may reflect the fact that they share the common precursor ornithine (Urano et al., 2009). The polyamine metabolic pathway also overlaps with other metabolic paths involved in the formation of diverse signalling molecules that are involved in plant stress responses. Thus, Spm, Spd and ethylene biosynthesis are connected through S-adenosylmethionine (SAM), a common precursor (Alcázar et al., 2010). Increased demand for ethylene would reduce the activity of decarboxylated SAM and therefore the concentration of Spm and Spd but would lead for all three cultivars, in agreement with the results shown in this paper, to an enhancement of the Put concentration, the obligate precursor molecule of Spd and Spm. An additional product of Put and Spd catabolism is $\gamma$-aminobutyric acid (GABA) that is produced through pyrroline (Cona et al., 2006). The levels of GABA, agmatine (a precursor of Put) and some components of the TCA cycle are enhanced under dehydration (Urano et al., 2009) together with an increase 
in Put content, which propose a metabolic connection between these paths in response to stress. In plants, two alternative pathways exist to produce Put from arginine i) via ornithine by arginase and ornithine decarboxylase (ODC) and ii) via agmatine by arginine decarboxylase (ADC), agmatine iminohydrolase (AIH) and N-carbamoyl-putrescine amidohydrolase (CPA) (Kusano et al., 2008). Transcript profiling using qRT-PCR has revealed that water stress and ABA treatment induces the expression of ADC genes (Alcázar et al., 2010) finally leading to an improved synthesis of Put and stomatal closure (An et al., 2008). Several studies (Flores \& Galston, 1982 and Legocka \& Kluk, 2005) reported for many species a Put accumulation in response to osmotic stress. The over expression of ADC genes from oat (Avena sativa) and Datura stramonium showed high accumulation of Put in the transgenic plants, which resulted in enhanced drought tolerance when compared with the wildtype genotypes (Capell et al., 2004). Arabidopsis plants indicated more drought tolerance by overexpression of ADC2 that conducted a higher level of DAC and induction of stomata closure (Alcázar et al., 2010). In fact, the enzymes DAO and PAO, involved in the PA catabolic pathway, play also a role in the ABA signalling pathway in stomata closure (An et al., 2008). AtPAO2, AtPAO3, and AtPAO4 expression in Arabidopsis are induced by ABA (Toumi et al., 2010). The activity of $\mathrm{CuAO}$ in Vicia faba guard cells is an important source of $\mathrm{H}_{2} \mathrm{O}_{2}$ production in ABAinduced stomatal closure (An et al., 2008). All these explanations support the conclusion that up-regulation of ADC genes and accumulation of Put under drought stress are abscisic acid (ABA)-dependent responses (Alcázar et al., 2010). In conclusion, the polyamine metabolism of all three cultivars of sweetpotato seems to be connected to several important hormonal and metabolic pathways involved in development and stress responses. However, not only the presented cascade of reactions, but the early and substantial adjustment of Santo Amaro at moderate drought seems to be the major reason to initiate and to minimize the impact of severe drought more as both other cultivars.

\section{Salinity}

High salinity is a significant environmental factor that affects large areas of cultivated land, causing a considerable reduction in global crop productivity (Ahuja et al., 2010). PAs were identified as important players in salt resistance of plants (Krishnamurthy \& Bhagwat, 1989; Groppa \& Benavides, 2008 and Alcázar et al., 2010). The physiological response and the polyamine composition of all three sweetpotato cultivars differed significantly under salinity stress compared to drought treatment. Although Abees presented again the highest sensitivity Mogamba cultivar replaced Santo Amaro cultivar as the most tolerant sweetpotato. The strong response of Abees (50\% growth reduction at $76.2 \mathrm{mM} \mathrm{NaCl}$ ) may be explained by the avoidance of $\mathrm{Na}^{+}$and $\mathrm{Cl}^{-}$accumulation (the lowest increase of LEC) leading to a more energy consuming adjustment with sugars and proline in case of salinity. This exhausting system can be demonstrated by the only transient decrease of RWC, chlorophyll content and transpiration in the course of increasing salinity.

Changes in polyamine composition, an increase of Put, up to moderate salinity $(100 \mathrm{mM}$ $\mathrm{NaCl}$ ) reflects the response to drought. However, high salinity led to a reversal from Put to Spd accumulation which leads in combination with the decrease of stomatal resistance and the subsequent increase of transpiration to lethal conditions. We assume that the still very high PA concentration reflects in Abees the reduction of the involvement in the stress response of important hormonal and metabolic pathways as discussed in the chapter drought case. Santo Amaro responded very much different to salinity as to drought stress. The Put concentration decreased steadily from low up to high salinity but Spd increased transiently up to $100 \mathrm{mM} \mathrm{NaCl}$ salinity. Zapata et al. (2004) investigated the effect of salinity on plant growth, ethylene production and polyamine levels in several crop species, Spinacia oleracea, Lactuca sativa, Cucumis melo, Capsicum annuum, Brassica oleracea, Beta vulgaris and Solanum lycopersicum. Krishnamurthy \& Bhagwat (1989) observed that salt resistance in rice was associated with increased levels of Spd and Spm, Flores et al. (1990) suggested that only Spd and Spm are involved in the protective response under stress conditions. In conformance with the results from Santo Amaro, it was found by several authors that PA levels altered with salinity and in most situations Put decreased while Spd and/or Spm enhanced (Gill \& Tuteja, 2010). Spd might be more useful to keep a high $\mathrm{K} / \mathrm{Na}$-selectivity or protect cellular structures such as proteins from coagulation or precipitation by salts and reflects 
mainly ion-specific effects. This assumption is confirmed by the fact that there is a correlation between overexpression of spermidin synthase (SPDS) and resistance to salinity (Capell et al., 2004). However, salinities above the reversal point of the Spd accumulation in Santo Amaro $(100 \mathrm{mM} \mathrm{NaCl})$ led to a reduction in total free PAs (Put+ Spd + Spm) and seemed to lead, similar as in Abees and in agreement with the results of Santa-Cruz (1997), to an unbalanced high demand for energy for osmotic adjustment and in consequence to a strong reduction in anabolism. It is fascinating that Mogamba was the only cultivar showing an increase in Put and Spd concentration up to treatment with $150 \mathrm{mM}$ $\mathrm{NaCl}$ salinity. This seems to reflect a combined response to physiological drought (an increase of Put) and salinity (an increase of Spd) up to the limit of salt resistance. In continuation of the former argumentation in Abees and Santo Amaro, we assume that Mogamba adapts as well to the osmotic stress as to ion specific stress. This fit to the observation that Mogamba was also the only cultivar with a strong increase of LEC up to $179.1 \%$ of the control (Abees: $108.3 \%$, Santo Amaro: $111.2 \%$ ). This denotes an uptake of substances with high electric conductivity such as $\mathrm{Na}^{+}$and $\mathrm{Cl}^{-}$and gives evidence for a comparable cheap osmotic adjustment. In summary, it is astonishing that Mogamba showed the overall picture of salt tolerance including both osmotic and ionic effects in contrast to Abees and Santo Amaro. However, it is not surprising that cultivars of a crop species present varying mechanisms of salt resistance. The variation in PAs levels was stated before between varieties of the same crop when Krishnamurthy \& Bhagwat (1989) found that the levels of diamine and polyamine differ among the investigated rice cultivars increased under salt stress.

\section{Conclusion}

Comparison of changes in PA patterns among different cultivars of a crop species under defined drought and salt stress conditions gives insight into whether analyses of PA contents can serve as a marker for tolerance to these stresses. Further studies will lead to the efficient exploitation of genetic resources with desirable stress resistance and the development of new approaches to enhance stress resistance. PAs could function as ideal targets for future crop improvement to cope with changing environments, nevertheless, additional information is required to clarify the mechanism of the complex regulation of PAs under abiotic stresses for enhancing tolerance to environmental stresses in sweetpotato. Although several possible models have been proposed, the exact physiological and molecular mechanisms by which PAs present protection remain indefinable.

Acknowledgment: The authors thank the International Potato Centre (CIP), Lima, Peru, for providing the sweetpotato genotypes. This work was supported by the German Academic Exchange Service (DAAD) grant to Mervat ElFar under the Alumni Re-Invitation Program.

Author contributions: Mervat El-Far. contributed to the experimental setup design, stress treatments experiments, polyamine extraction and analysis; Hans-Werner Koyro. contributed to the concept and design of the stresses experiments and physiological data interpretation; Thomas Berberich contributed to the HPLC analysis and polyamine data interpretation. All the authors contributed to the writing of the manuscript.

\section{References}

Ahuja, I., de Vos, R.C., Bones, A.M. and Hall, R.D. (2010) Plant molecular stress responses face climate change. Trends Plant Sci. 15(12), 664-674.

Alcázar, R., Altabella, T., Marco, F., Bortolotti, C., Reymond, M., Koncz, C. and Tiburcio, A.F. (2010) Polyamines: Molecules with regulatory functions in plant abiotic stress tolerance. Planta, 231(6), 1237-1249.

Alcázar, R., Cuevas, J.C., Planas, J., Zarza, X., Bortolotti, C., Carrasco, P. and Altabella, T. (2011) Integration of polyamines in the cold acclimation response. Plant Sci. 180(1), 31-38.

An, Z., Jing, W., Liu, Y. and Zhang, W. (2008) Hydrogen peroxide generated by copper amine oxidase is involved in abscisic acid-induced stomatal closure in Vicia faba. J. Exp. Bot. 59(4), 815-825.

Berberich, T., Sagor, G.H.M. and Kusano, T. (2015) Polyamines in plant stress response. In: "Polyamines, A Universal Molecular Nexus for Growth, Survival, and Specialized Metabolism", Kusano, T. and Suzuki, H. (Eds.), pp 155-168.

Biswas, M.S. and Mano, J. (2015) Lipid peroxide- 
derived short-chain carbonyls mediate $\mathrm{H}_{2} \mathrm{O}_{2}$ induced and $\mathrm{NaCl}$ - induced programmed cell death in plants. Plant Physiol. 168, 885-898.

Capell, T., Bassie, L. and Christou, P. (2004) Modulation of the polyamine biosynthetic pathway in transgenic rice confers tolerance to drought stress. Proc. Nat. Acad. Sci. 101(26), 9909-9914.

Cona, A., Rea, G., Angelini, R., Federico, R. and Tavladoraki, P. (2006) Functions of amine oxidases in plant development and defence. Trends Plant Sci. 11(2), 80-88.

El-Far, M.M.M. and Koyro, H.W. (2014) Differences in chilling tolerance among genotypes of sweetpotato (Ipomoea batatas (L.) Lam.). Arab J. Biotech. 17(2), 155-166.

EL-Bastawesy, A., Hareedy, L.A. and El-Far, M.M.M. (2008) Chemical and technological evaluation of some sweetpotato varities. Arab Univ. J. Agric. Sci. 16, 87-96.

FAO (2008) Expert consultation on nutrition indicators for biodiversity-1. In: Food Composition, FAO, Rome.

FAO (2012) Statistical Yearbook 2013-World Food and Agriculture. FAO.

Flores, H.E. and Galston, A.W. (1982) Polyamines and plant stress: Activation of Putrescine biosynthesis by osmotic shock. Science, 217(4566), 1259-1261.

Flores, H.E., Arteca, R.N. and Shannon, J.C. (1990) Polyamines and ethylene: biochemistry, physiology, and interactions: proceedings, $5^{\text {th }}$ Annual Penn State Symposium in Plant Physiology, May 17-19, 1990. American Society of Plant Physiologists.

Gill, S.S. and Tuteja, N. (2010) Polyamines and abiotic stress tolerance in plants. Plant Signal and Behaviour, 5, 26-33.

Groppa, M.D. and Benavides, M.P. (2008) Polyamines and abiotic stress:recent advances. Amino Acids, $\mathbf{1}$, $35-45$.

Harindra Champa, W.A., Gilla, M.I.S., Mahajanb, B.V.C. and Bedic, S. (2015) Exogenous treatment of spermine to maintain quality and extend post harvest life of table grapes (Vitis vinifera L.) cv. Flame Seedless under low temperature storage.
LWT Food Sci. Technol. 60, 412-419.

Kasukabe, Y., He, L., Watakabe, Y., Otani, M., Shimada, T. and Tachibana, S. (2006) Improvement of environmental stress tolerance of sweet potato by introduction of genes for spermidine synthase. Plant Biotech. 23(1), 75-83.

Koti, S., Reddy, K.R., Kakani, V.G., Zhao, D. and Gao, W. (2007) Effects of carbon dioxide, temperature and ultraviolet-B radiation and their interactions on soybean (Glycine max L.) growth and development. Environ. Exp. Bot. 60(1), 1-10.

Krishnamurthy, R. and Bhagwat, K.A. (1989) Polyamines as modulators of salt tolerance in rice cultivars. Plant Physiol. 91(2), 500-504.

Kubota, F. (2003) The effects of drought stress and leaf ageing on leaf photosynthesis and electron transport in photosystem 2 in sweet potato (Ipomoea batatas Lam.) cultivars. Photosynthetica, 41(2), 253-258.

Kusano, T., Berberich, T., Tateda, C. and Takahashi, Y. (2008) Polyamines: essential factors for growth and survival. Planta, 228(3), 367-381.

Landau, G., Ran, A., Bercovich, Z., Feldmesser, E., Horn-Saban, S., Korkotian, E., Jacob-Hirsh, J., Rechavi, G., Ron, D. and Kahana, C. (2012) Expression profiling and biochemical analysis suggest stress response as a potential mechanism inhibiting proliferation of polyamine-depleted cells. J. Biol. Chem. 287(43), 35825-35837.

Laurie, S., Faber, M., Adebola, P. and Belete, A. (2015) Biofortification of sweet potato for food and nutrition security in South Africa. Food Res. Int. 76, 962-970.

Legocka, J. and Kluk, A. (2005) Effect of salt and osmotic stress on changes in polyamine content and arginine decarboxylase activity in Lupinus luteus seedlings. J. Plant Physiol. 162(6), 662-668.

Liu, H.P., Dong, B.H., Zhang, Y.Y., Liu, Z.P. and Liu, Y.L. (2004) Relationship between osmotic stress and the levels of free, conjugated and bound polyamines in leaves of wheat seedlings. Plant Sci. 166(5), 1261-1267.

Liu, J.H., Kitashiba, H., Wang, J., Ban, Y. and Moriguchi, T. (2007) Polyamines and their ability to provide environmental stress tolerance to plants. 
Plant Biotech. 24(1), 117-126.

Mostofa, M.G.,Yoshida, N. and Fujita, M. (2014) Spermidine pretreatment enhances heat tolerance in rice seedlings through modulating antioxidative and glyoxalase systems. Plant Growth Regul. 73, $31-44$.

Naka, Y., Watanabe, K., Sagor, G.H.M., Niitsu, M., Pillai, M.A., Kusano, T. and Takahashi, Y. (2010) Quantitative analysis of plant polyamines including thermospermine during growth and salinity stress. Plant Physiol. Biochem. 48(7), 527-533.

Ndolo, P.J., Mcharo, T., Carey, E.E., Gichuki, S.T. and Ndinya, C. (2001) Participatory on-farm evaluation of Sweet potato varieties in western Kenya. African Crop Sci. J. 9, 41-48.

Sagor, G.H.M., Berberich, T., Takahashi, Y., Niitsu, M. and Kusano, T. (2013) The polyamine spermine protects Arabidopsis from heat stress-induced damage by increasing expression of heat shockrelated genes. Transgenic Res. 22(3), 595-605.

Santa-Cruz, A., Acosta, M., Pérez-Alfocea, F. and Bolarin, M.C. (1997) Changes in free polyamine levels induced by salt stress in leaves of cultivated and wild tomato species. Physiol. Plantarum, 101(2), 341-346.

Shabala, S. and Munns, R. (2017) Salinity stress: Physiological constraints and adaptive mechanisms. In: "Plant Stress Physiol.", pp. 24-63. $2^{\text {nd }}$ ed. CABI, Wallingford.

Smart, R.E. and Bingham, G.E. (1974) Rapid estimates of relative water content. Plant Physiol. 53(2), 258260.

Tabor, C.W. and Tabor, H. (1985) Polyamines in microorganisms. Microbiol. Rev. 49(1), 81.

Toumi, I., Moschou, P.N., Paschalidis, K.A., Bouamama, B., Salem-Fnayou, A.B., Ghorbel, A.W. and Roubelakis-Angelakis, K.A. (2010) Abscisic acid signals reorientation of polyamine metabolism to orchestrate stress responses via the polyamine exodus pathway in grapevine. J. Plant Physiol. 167(7), 519-525.

Urano, K., Maruyama. K., Ogata, Y., Morishita, Y., Takeda, M., Sakurai, N., Suzuki, H., Saito, K., Shibata, D., Kobayashi, M., Yamaguchi-Shinozaki, K. and Shinozaki, K. (2009) Characterization of the ABA regulated global responses to dehydration in Arabidopsis by metabolomics. Plant J. 57, 1065 1078.

Yooyongwech, S., Samphumphuang, T., Tisarum, R., Theerawitaya, C. and Cha-um, S. (2016) Arbuscular mycorrhizal fungi (AMF) improved water deficit tolerance in two different sweet potato genotypes involves osmotic adjustments via soluble sugar and free proline. Sci. Hortic. (Amsterdam), 198, $107-$ 117.

Zapata, P.J., Serrano, M., Pretel, M.T., Amorós, A., Botella, M.Á. (2004) Polyamines and ethylene changes during germination of different plant species under salinity. Plant Sci, 167(4), 781-788.

(Received 18/12/2018; accepted 27/2/2019) 


\section{التغير في مستويات انتاج عديدات الأمين الحره لثُلاثه من أصناف البطاطا تحت ظروف الأجهاد البيئي المختلفة فيتو}

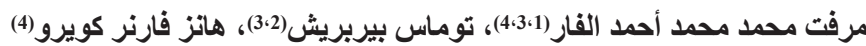

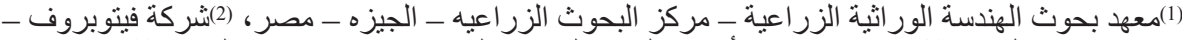

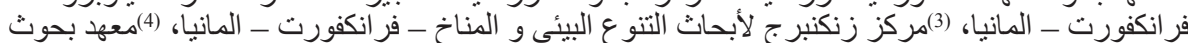
البيئه النباتيه - جامعة جيسين - المانيا،

تم اخضاع ثلاثه من أصناف البطاطا (ابيس- موجمبا- سانتو أمارو) لظروف جفاف من مناف معتدله (0.5- ميجاباسكال)

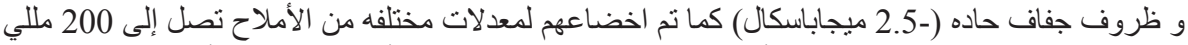

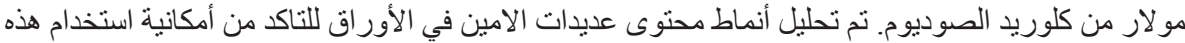

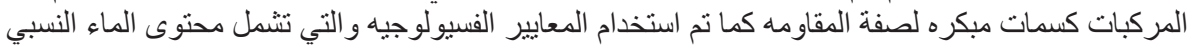

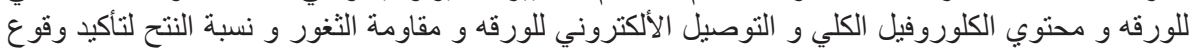

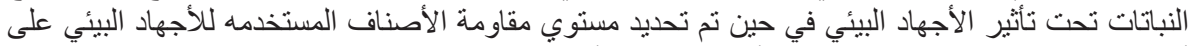

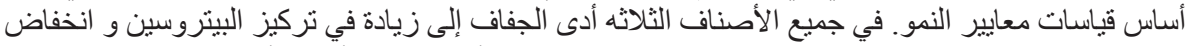

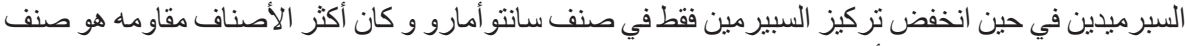

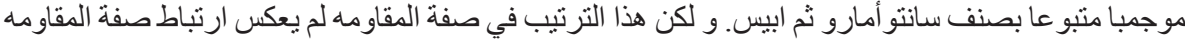

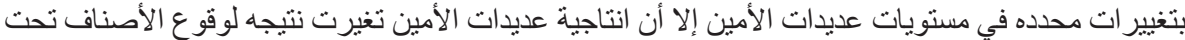

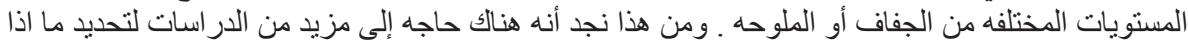
كانت عديدات الأمين تتغير كرد فعل على الأجهاد البيئي او كآليه للحمايه. 